\title{
The prevalence of clinically significant sleep apnoea syndrome in the Netherlands
}

\author{
A Knuistingh Neven, H A M Middelkoop, B Kemp, H A C Kamphuisen, M P Springer
}

\begin{abstract}
Background-Figures for the prevalence of sleep apnoea syndrome range from $0.3 \%$ to $8.5 \%$. These widely ranged estimates are probably due to differences in the definitions used, study designs, and study populations. A study was undertaken to determine the lower limit of the prevalence of clinically significant sleep apnoea syndrome.

Methods-A cross sectional survey by postal questionnaire was carried out in a general practice of a small town in which three doctors serve $93 \%$ of its population of 6747 inhabitants of all ages. All men aged 35 and over and women aged 50 and over were invited to fill in a specially designed questionnaire on snoring and sleep. All men and women whose answers suggested the possible occurrence of sleep apnoea were invited to undergo further investigation. Oronasal thermistry was performed in the subjects' homes and the results were scored to provide an apnoea index (AI). Those subjects with an AI of $\geqslant 5$ were referred to a sleep laboratory for investigation by polysomnography.
\end{abstract}

Results-Of the 2466 questionnaires issued, $2182(88.5 \%)$ were completed and returned. The occurrence during the previous three months of regular snoring, together with daytime sleepiness and/or partners' observation of interruptions in breathing at night, was reported by 194 subjects (169 men, 25 women). In 173 subjects oronasal thermistry applied in their homes provided satisfactory recordings and, of these, 24 men and one woman had an AI of $\geqslant 5$. Analysis of the polysomnographic findings showed that 14 men and one woman met the criteria for sleep apnoea syndrome. Scrutiny of their case records disclosed that in seven men this was clinically significant.

Conclusions-Our findings suggest that the prevalence of clinically significant sleep apnoea syndrome in men aged 35 and over is at least $0.45 \%$. Extrapolation to the population of the Netherlands suggests that at least 16000 men suffer from sleep apnoea syndrome that should be relieved by medical care. A large proportion of these subjects remains to be diagnosed. (Thorax 1998;53:638-642)

Keywords: sleep apnoea syndrome; prevalence; oronasal thermistry
Sleep apnoea refers to repetitive episodes of absence of respiration during sleep. Sleep apnoea syndrome is that condition in which episodes of sleep apnoea give rise to deleterious effects of a mental or physical nature. ${ }^{1-3}$ Among the most common of these are excessive daytime sleepiness, fatigue, and cardiovascular morbidity.

Estimates of the prevalence of sleep apnoea syndrome give widely different figures, ranging from $0.3 \%-8.5 \%,{ }^{4-10}$ probably because of differences in definitions, in the design of the studies and the investigations performed, and in the age, sex and other characteristics of the populations surveyed.

It may well be assumed that in a high proportion of subjects who would meet the criteria of sleep apnoea syndrome the condition is never recognised. In the present study we categorised subjects with readily recognisable manifestations of sleep apnoea syndrome as having it in a clinically significant form.

Now that the potential danger of sleep apnoea syndrome is recognised and therapeutic measures are available, including continuous positive air pressure (CPAP), it is clearly important to identify it and estimate its frequency in the general population. The general practice setting provides an ideal opportunity for achieving both these objectives.

It is generally agreed that a definitive diagnosis of sleep apnoea syndrome depends on certain criteria whose presence can only be elicited by polysomnography performed in a specialised sleep laboratory. ${ }^{211}{ }^{12}$ However, we have shown previously that a one night monitoring of breathing by oronasal thermistry may be carried out in subjects' homes and that it is a valuable screening procedure for population surveys. ${ }^{1}$ An oronasal thermistor monitors breathing by recording changes in temperature of inspired and expired air. Its signals are transmitted to a recording device. It is sufficiently small and light in weight to be worn without causing any disturbance of sleep.

We report here the findings of a study whose principal objective was to determine the prevalence of clinically significant sleep apnoea syndrome in the population of a general practice in the Netherlands. The study comprised three stages: (1) distribution of a questionnaire, (2) oronasal thermistry and estimation of an apnoea index in subjects whose answers were suggestive of sleep apnoea syndrome and, in those found to have an apnoea index of 5 or more, (3) referral to a sleep laboratory for polysomnography. 


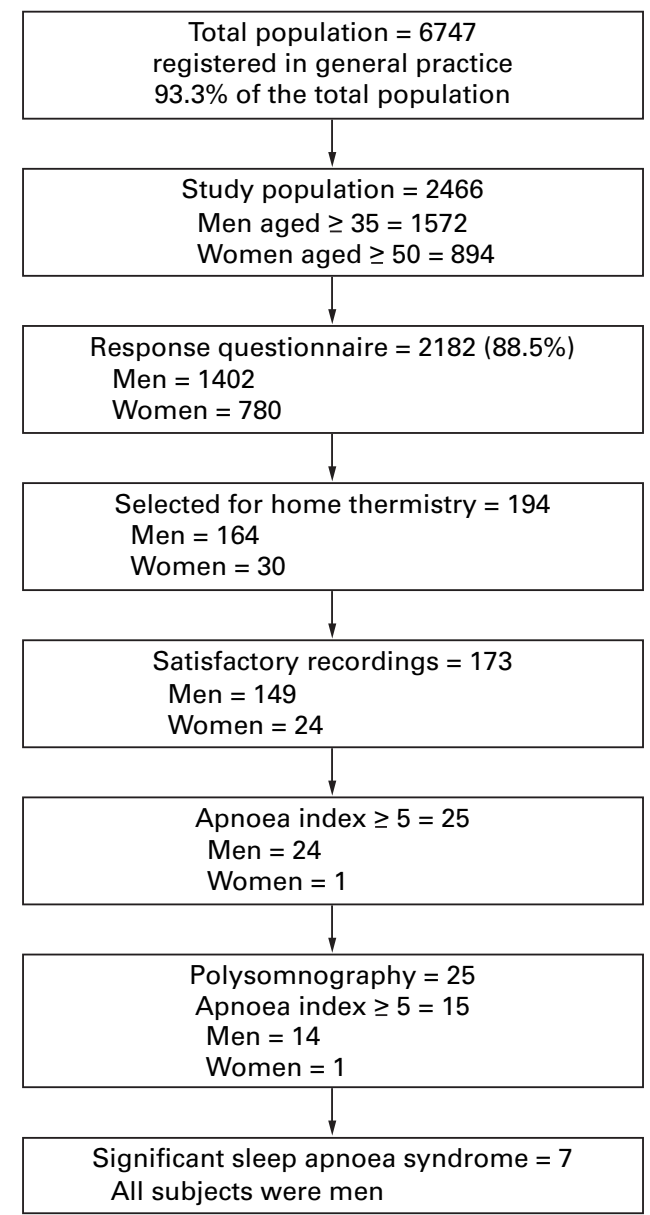

Figure 1 Flow chart of the sleep apnoea syndrome prevalence study.

\section{Methods}

The observational design of the study was on a cross sectional basis. Figure 1 presents a flow chart of the study. The study was approved by the ethics committee for Medical Research of the Leiden University Hospital.

\section{STUDY POPULATION}

The study was conducted in Krimpen a/d Lek, the Netherlands. This a small town near Rotterdam of 6747 inhabitants (3399 men and 3348 women). At the time of the study $93.3 \%$ of all inhabitants were registered in a general group practice of three doctors of which the author is one. The population was representative of the Dutch population with regard to sex and age characteristics. ${ }^{13}$

\section{SLEEP QUESTIONNAIRE}

Every man aged 35 and over and woman aged 50 and over who was registered with the practice was sent an introductory letter and a specially prepared questionnaire about his or her sleep. This questionnaire was designed to elicit information from the subjects themselves or from their partners about the occurrence within the previous three months of snoring, cessation of breathing during sleep, tiredness or sleepiness during the day, and other symptoms related to sleep apnoea syndrome and cardiovascular problems. If no reply had been received after four weeks a first reminder was sent and a final reminder was sent after eight weeks.

Each returned questionnaire was entered into two separate databases. After entry of all questionnaires the two databases were compared and any discrepancy was discussed and subsequently corrected. The body mass index (BMI) was calculated of all the subjects based on the answers for height and weight.

The completed questionnaires were scrutinised for answers which might indicate the occurrence of sleep apnoea syndrome. Subjects were selected for further investigation if they reported habitual snoring (more than three nights per week) according to the quantitative Basic Nordic Sleep Questionnaire. ${ }^{14}{ }^{15}$ The subjects were only selected if besides habitual snoring they reported: (1) excessive daytime sleepiness - presence of inappropriate and undesirable sleepiness during waking hours considered excessive when the score was $\geqslant 3$ on a four point rating scale (never, sometimes, often, always present), and/or (2) nocturnal respiratory arrests (partner report; $\geqslant 3$ scored on a similar ordinal scale).

\section{ORONASAL THERMISTRY}

All subjects who fulfilled our criteria were invited to undergo overnight oronasal thermistry in their homes unless there was any medical or other contraindication. Those who agreed were given a full explanation of oronasal thermistry and were requested not to make any alteration in their usual pattern of sleep and daytime activities. On the evening of the test they were shown how to apply the thermistor in front of their mouth and nose, how to switch the recorder on and off, and how to activate the event marker when they turned out their light before going to sleep and when they awoke next morning. The thermistor was connected to a portable modified four-channel Medilog recorder. Breathing was recorded for one hour while the subject was awake and then throughout the period of his or her sleep.

Recordings were considered satisfactory if they were of five or more hours' duration without artifact or signal dropout. An experienced technician examined the recordings and calculated an apnoea index for every subject - that is, the number of apnoeic periods lasting 10 seconds or more, occurring per hour of sleep. Apnoea was defined as a $70 \%$ or greater reduction in amplitude of airflow compared with that of the breath immediately preceding it. ${ }^{1}$

POLYSOMNOGRAPHY

Those subjects in whom thermistry gave an apnoea index of 5 or more were referred for polysomnography, performed in either the Department of Neurology of the Leiden University Hospital or in the Sleep Center of the Westeinde Hospital in the Hague. The investigations, which were carried out throughout the period of nocturnal sleep, comprised electroencephalographic, electro-oculographic, electromyographic (submental), and electrocardiographic recordings, thoracic and abdominal respiratory movements by strain gauges, 
Table 1 Results after polysomnography (PSG). AI-PSG is apnoea index by one or two polysomnographic recordings. AI-HT is apnoea index by home thermistry. The maximum decrease of oxygen saturation $\left(O_{2} \downarrow \geqslant 5 \%\right)$, presence of arousal and cardiac dysrhythmia (ECG) during PSG are shown

\begin{tabular}{|c|c|c|c|c|c|c|c|c|c|c|}
\hline No & $\operatorname{Sex}$ & Age & $A I-H T$ & $A I-P S G$ & $B M I$ & $O_{2} \downarrow \geqslant 5 \%$ & Arousals & $E C G$ & Legs & Diagnosis \\
\hline 1 & M & 46 & 6 & 4 & 32 & - & - & - & - & - \\
\hline 2 & M & 54 & 19 & 6 & 23 & $13 \%$ & + & + & PLMD & SAS \\
\hline 3 & M & 51 & 9 & 11 & 30 & $30 \%$ & + & + & - & SAS \\
\hline 4 & M & 41 & 5 & 21 & 26 & $7 \%$ & + & + & - & SAS \\
\hline 5 & $M$ & 61 & 15 & 32 & 28 & $8 \%$ & + & - & - & SAS \\
\hline 6 & $M$ & 65 & 23 & 19 & 27 & $9 \%$ & + & + & PLMD & SAS \\
\hline 7 & M & 43 & 35 & 45 & 29 & $10 \%$ & + & - & - & SAS \\
\hline 8 & M & 77 & 5 & 0 & 30 & - & - & - & - & - \\
\hline 9 & $M$ & 47 & 7 & 2 & 34 & $6 \%$ & - & + & - & - \\
\hline 10 & $M$ & 48 & 11 & 14 & 26 & $13 \%$ & - & - & - & SAS \\
\hline 11 & M & 47 & 5 & 0 & 26 & - & + & - & PLMD & - \\
\hline 12 & M & 68 & 6 & 0 & 28 & - & + & - & PLMD & - \\
\hline 13 & $\mathrm{~F}$ & 63 & 10 & 6 & 27 & - & + & - & PLMD & SAS \\
\hline 14 & M & 48 & 6 & 8 & 27 & $15 \%$ & + & + & - & SAS \\
\hline 15 & M & 67 & 6 & 12 & 26 & $13 \%$ & + & - & - & SAS \\
\hline 16 & M & 39 & 10 & 0 & 26 & - & + & - & - & - \\
\hline 17 & $M$ & 53 & 8 & 13 & 19 & $6 \%$ & + & - & - & SAS \\
\hline 18 & $M$ & 53 & 7 & 0 & 26 & - & + & - & PLMD & - \\
\hline 19 & M & 41 & 6 & 3 & 21 & $15 \%$ & - & - & - & - \\
\hline 20 & $M$ & 67 & 5 & 0 & 25 & - & - & - & PLMD & - \\
\hline 21 & M & 36 & 18 & 32 & 29 & $30 \%$ & + & + & PLMD & SAS \\
\hline 22 & M & 45 & 30 & 35 & 28 & - & + & - & - & SAS \\
\hline 23 & M & 58 & 6 & 0 & 24 & - & - & - & - & - \\
\hline 24 & M & 62 & 7 & 16 & 26 & $12 \%$ & + & + & - & SAS \\
\hline 25 & $M$ & 67 & 8 & 22 & 24 & $22 \%$ & + & - & PLMD & SAS \\
\hline
\end{tabular}

PSG = polysomnography $\mathrm{AI}=$ apnoea index $\mathrm{HT}=$ home thermistry; $\mathrm{BMI}=$ body mass index $\mathrm{PLMD}=$ periodic leg movement disorder; SAS = sleep apnoea syndrome.

oronasal thermistry, and monitoring oxygen saturation by pulse oximetry. In addition, electromyographic recordings were made from the anterior tibialis muscles to detect periodic leg movements disorder according to the diagnostic criteria of the ICDS. ${ }^{1}$

During polysomnography arousals (an abrupt change from a deeper stage of nonREM sleep to a "lighter" stage, or from REM sleep toward wakefulness), respiration and cardiac rhythm were recorded. A decrease in oxygen saturation of $5 \%$ or more from the baseline level was regarded as clinically significant. The AI was calculated from the polysomnographic recordings. A second polysomnographic recording was conducted within one month if the first recording had resulted in an AI of $<5$.

The criteria used in the diagnosis of sleep apnoea syndrome by polysomnography comprised an AI of $\geqslant 5$ or more together with frequent arousals, cardiac dysrhythmias, and oxygen desaturations of $5 \%$ or more from baseline associated with the apnoeic events. ${ }^{2}$

In all subjects who fulfilled these polysomnographic criteria their case records were scrutinised to determine in which of them the sleep apnoea syndrome could be considered clinically significant. The subjects were exposed to extensive history taking about present symptoms and, if necessary, their partner was consulted.

\section{Results}

Questionnaires were completed and returned by 1402 men and 780 women, representing $88.5 \%$ of the total number of subjects to whom they were sent. Apnoeic episodes, reported by their partners, were much more common in men $(5.3 \%)$ than in women $(1.5 \%)$. Almost twice as many men $(38.7 \%)$ than women $(20.1 \%)$ reported snoring on three or more nights per week. Smaller differences between sexes were found in excessive daytime sleepi- ness (men 13.4\%, women 9.6\%). The mean (SD) BMI of all responders, the non-snoring group and the snoring group was 25.46 (3.34), 25.21 (3.26), and 26.96 (3.40), respectively, and did not differ significantly.

Evaluation of the answers to the questionnaires suggested that 194 subjects (164 men, 30 women) might have sleep apnoea syndrome. Of these, 156 men and 26 women agreed to undergo oronasal thermistry at home. Two subjects declined, two were no longer resident in the neighbourhood, and eight were excluded because of medical contraindications such as malignancy, severe asthma, and mental disorders. In 173 subjects oronasal thermistry provided satisfactory recordings. The longest apnoeic event lasted 131 seconds, while the total duration of all apnoeic episodes in another subject amounted to almost $95 \mathrm{~min}$ utes. An AI of $\geqslant 5$ or more was found in 24 men and one woman. These subjects were referred for comprehensive investigation by polysomnography. Their BMI was not significantly different from those with an AI of $<5$ (mean (SD) BMI of group with $\mathrm{AI}<5: 26.01$ (3.08); mean (SD) BMI of group with AI $\geqslant 5: 26.32$ (3.21)).

Twelve subjects $(11 \mathrm{men})$ met the diagnostic criteria for sleep apnoea syndrome after the first polysomnographic investigation. Twelve of the 13 subjects who did not meet the criteria for having sleep apnoea syndrome agreed to undergo a second polysomnographic recording (one patient declined). In three additional subjects the diagnosis of sleep apnoea syndrome could be made (table 1 ). In nine patients periodic leg movements disorder was found, five of them in combination with sleep apnoea syndrome.

Analysis of all patients who met the polysomnographic criteria for the diagnosis of sleep apnoea syndrome disclosed that seven of the 15 patients were suffering from a clinically significant sleep apnoea syndrome. The main points 
Table 2 Characteristics of seven patients with clinically significant sleep apnoea syndrome

\begin{tabular}{|c|c|c|c|c|}
\hline No & $A I$ & Complaints & Type of apnoeas & Miscellaneous \\
\hline 18 & 14 & Daytime sleepiness concentration problems & Central obstructive & \\
\hline 6 & 19 & $\begin{array}{l}\text { Daytime sleepiness tiredness } \\
\text { Loss of libido }\end{array}$ & Central & PLMD \\
\hline 25 & 22 & $\begin{array}{l}\text { Dry throat in the morning } \\
\text { Tiredness }\end{array}$ & Mainly central & PLMD \\
\hline 25 & 22 & $\begin{array}{l}\text { Loss of libido } \\
\text { Morning headache } \\
\text { Dry throat in the morning }\end{array}$ & Mramy central & FLIVI \\
\hline 9 & 32 & Daytime sleepiness & Central & \\
\hline 21 & 32 & $\begin{array}{l}\text { Daytime sleepiness } \\
\text { Tiredness }\end{array}$ & $\begin{array}{l}\text { Obstructive } \\
\text { Central } \\
\text { Mixed }\end{array}$ & PLMD \\
\hline 22 & 35 & $\begin{array}{l}\text { Tiredness } \\
\text { Insomnia } \\
\text { Irritable }\end{array}$ & $\begin{array}{l}\text { Mainly central } \\
\text { Obstructive }\end{array}$ & \\
\hline 7 & 45 & $\begin{array}{l}\text { Daytime sleepiness } \\
\text { Loss of libido } \\
\text { Dry throat in the morning }\end{array}$ & $\begin{array}{l}\text { Obstructive } \\
\text { Mixed } \\
\text { Central }\end{array}$ & Myocardial infarction \\
\hline
\end{tabular}

$\mathrm{AI}=$ apnoea index PLMD = periodic leg movement disorder.

are presented in table 2. A mixture of apnoea types (obstructive, central, mixed) was present.

\section{Discussion}

From the data obtained in the three stage survey we have estimated the prevalence of clinically significant sleep apnoea syndrome to be at least $0.45 \%$ in men aged 35 and over.

LIMITATIONS OF THE STUDY

By selecting subjects for thermistry based on results of the questionnaires it is possible to miss subjects with sleep apnoea syndrome. The criteria for age (35 years and older for men and 50 years and older for women) are arbitrary. Thus, it is conceivable that younger persons are affected too. Merely selecting on snoring combined with excessive daytime sleepiness and/or partner reports for cessations of breathing is also arbitrary. However, these criteria were recently emphasised by Strollo and Rogers. ${ }^{16}$ Moreover, the questionnaire response was high $(88.5 \%)$, the monitoring of $94 \%$ of the patients by thermistry and the full cooperation for polysomnography are strong arguments in favour of this method, and this suggests that the results are valid. Selection bias is not likely for reasons already mentioned. In our study underestimation rather than overestimation of the prevalence is the more likely result.

The choice of home thermistry was a compromise. All night polysomnography is very costly and labour intensive and is therefore not suitable for studies in large populations. Thermistry yields a qualitative and therefore limited measurement of airflow. Only apnoeic episodes can be assessed. Hypopnoeas cannot be measured with this technique. A one night monitoring of respiration with an oronasal thermister is useful for screening purposes, but valid clinical conclusions only based on these results are not possible. ${ }^{1}$ Polysomnography, in which sleep stages and arousals are recorded, is the preferred method for the definitive diagnosis of the sleep apnoea syndrome. ${ }^{12}$ In accordance with previous reports home thermistry is not burdensome for patients, it does not interfere with sleep, and it results in an acceptable proportion of interpretable nights. ${ }^{1}$

\section{PREVALENCE}

Our figure for prevalence of sleep apnoea syndrome is in line with those studies comprising clinically significant syndromes (table 3 ). In our study significant syndromes are prevalent in $0.45 \%$ of the men aged 35 and over. In other comparable studies the figures for men ranged from $0.3 \%$ to $1.3 \% .^{49}$ Stradling et $a l^{5}$ screened 1001 men with oximetry. However, some authors have stated that only using oximetry may result in an underestimation. ${ }^{17}{ }^{18}$ Studies resulting in a high prevalence comprise figures of sleep apnoea without clinical symptoms. ${ }^{6-1019}$ These figures suggest that asymptomatic cessations of breathing are common. Further research into the evolution of asymptomatic apnoeas should be performed.

The population we studied is representative of the Dutch population. ${ }^{13}$ Consequently, based on previous remarks about the limitations of this study, we determined the lower limit of the prevalence of sleep apnoea syndrome in the Netherlands. This suggests that in the Netherlands at least 16000 men suffer from sleep apnoea syndrome who should, if possible, be relieved by medical care.

Table 3 Prevalence of snoring, sleep apnoea and sleep apnoea syndrome in males

\begin{tabular}{|c|c|c|c|c|c|c|}
\hline Study & Age & $\begin{array}{l}\text { Habitual } \\
\text { snoring (\%) }\end{array}$ & $\begin{array}{l}\text { Sleep apnoea } \\
(\%)\end{array}$ & $\begin{array}{l}\text { Sleep apnoea } \\
+ \text { EDS (\%) }\end{array}$ & $\begin{array}{l}\text { Significant sleep } \\
\text { apnoea syndrome } \\
(\%)\end{array}$ & Remarks \\
\hline Lavie et al (1983) & $\geqslant 21$ & - & - & - & 0.9 & Selection bias? Industrial workers \\
\hline Gislason et al $(1988)^{9}$ & $30-69$ & 15.6 & 2 & - & 1.3 & $10 / 15$ with desaturations. Selection bias? \\
\hline Cirignotta et al (1989) ${ }^{10}$ & $30-69$ & 10.9 & 4 & - & ? & Selection bias? \\
\hline Stradling et al $(1991)^{5}$ & $35-65$ & 23 & 5 & - & 0.3 & Oximetry as screening tool \\
\hline Jennum et al $(1992)^{6}$ & $30-60$ & 19.1 & 10.9 & 1.9 & $?$ & Plethysmography as screening tool \\
\hline Young et al $(1993)^{8}$ & $30-60$ & 44 & 24 & 4 & ? & Selection bias? State employees \\
\hline Bearpark et al $(1993)^{7}$ & $40-65$ & - & 8.5 & - & ? & MESAM 4 as screening tool \\
\hline Present study & $\geqslant 35$ & 22 & 1.7 & 0.9 & 0.45 & Thermistry as screening method \\
\hline
\end{tabular}

EDS $=$ excessive daytime sleepiness 
In conclusion, the prevalence of clinically significant sleep apnoea syndrome is estimated to be at least $0.45 \%$ in men aged 35 and over. This figure is in accordance with other studies which studied clinically significant syndromes only. High prevalence figures in the literature are usually due to sleep apnoea without clinical symptoms, hence asymptomatic apnoeas are probably common.

In the present study six out of seven patients with clinically significant symptoms were successfully treated with CPAP, nasal surgery, or general measures such as dietary control of weight and abstinence from alcohol.

We thank Professor Jan Vandenbroucke and Dr Ian Gregg for their help in preparing this article.

1 Middelkoop HAM, Knuistingh Neven A, Wetering S van, et al. No significant night-to-night variability of homeal. No significas in night-to-night variability of homerecorded apnoeas in 22 subjects with suspected obstructive

2 Thorpy MJ, ed. The international classification of sleep Thorpy MJ, ed. The international classification of sleep
disorders. Rochester: American Sleep Disorders Associdisorders. R.

3 McNicholas WT. Diagnostic criteria for the sleep apnoea syndrome: time for consensus? Eur Respir F 1996;9:634-5.

4 Lavie P. Incidence of sleep apnea in a presummably healthy working population: a significant relationship with excessive daytime sleepiness. Sleep 1983;6:312-8

5 Stradling JR, Crosby JH. Predictors and prevalence of obstructive sleep apnoea and snoring in 1001 middle aged men. Thorax 1991;46:85-90.
6 Jennum P, Sjol A. Epidemiology of snoring and obstructive sleep apnoea in a Danish population, age 30-60. F Sleep Res 1992; apnoea in

7 Bearpark H, Elliott L, Grunstein R, et al. Occurrence and correlates of sleep disordered breathing in the Australian town of Busselton: a preliminary analysis. Sleep 1993;16: S3-5.

8 Young TJ, Palta M, Dempsey J, et al. The occurrence of sleep-disordered breathing among middle-aged adults. $N$ Engl f Med 1993;328:1230-5.

9 Gislason T, Almquist M, Eriksson G, et al. Prevalence of sleep apnea syndrome among Swedish men: an epidemiological study. F Clin Epidemiol 1988;41:571-6.

10 Cirignotta F, D'Alessandro R, Partinen M, et al. Prevalence of every night snoring and obstructive sleep apnoeas among 30-69-year-old men in Bologna, Italy. Acta Psychiatr Scand 1980;79:366-72.

11 Douglas NJ. The sleep apnoea/hypopnoea syndrome and snoring. BM7 1993;306:1057-60

12 Deegan PC, McNicholas WT. Predictive value of clinical features for the obstructive sleep apnoea syndrome. Eur Respir 7 1996;9:117-24.

13 Middelkoop HAM, Smilde-van den Doel DA, Knuistingh Neven A, et al. Subjective sleep characteristics of 1485 males and females aged 50-93: effects of sex and age, and factors related to self evaluated quality of sleep. $\mathcal{F}$ Gerontol Med Sci 1996;M108-15.

14 Partinen M. Epidemiology of habitual snoring and obstructive sleep apnea. F Sleep Res 1992:1(Suppl 1):172.

15 Lugaresi S, Partinen M. Prevalence of snoring. In: Saunders NA, Sullivan CE, eds. Sleep and breathing. New York: Marcel Dekker, 1994.

16 Strollo PJ, Rogers RM. Obstructive sleep apnea. N Engl f Med 1996;334:99-104.

17 Douglas NJ, Thomas S, Jan MA. Clinical value of polysomnography. Lancet 1992;339:347-50.

18 Yamashiro Y, Kryger MH. Nocturnal oximetry: is it a screening tool for sleep disorders? Sleep 1995;18:176-71.

19 Davies RJO, Stradling JR. The epidemiology of sleep apnoea. Thorax 1996;51:S65-70. 